\title{
Two Heteromeric Kv1 Potassium Channels Differentially Regulate Action Potential Firing
}

\author{
Paul D. Dodson, Matthew C. Barker, and lan D. Forsythe \\ Department of Cell Physiology and Pharmacology, University of Leicester, Leicester, LE1 9HN, United Kingdom
}

Low-threshold voltage-gated potassium currents $\left(I_{\mathrm{LT}}\right)$ activating close to resting membrane potentials play an important role in shaping action potential (AP) firing patterns. In the medial nucleus of the trapezoid body (MNTB), I IT ensures generation of single APs during each EPSP, so that the timing and pattern of AP firing is preserved on transmission across this relay synapse (calyx of Held). This temporal information is critical for computation of sound location using interaural timing and level differences. ILT currents are generated by dendrotoxin-I-sensitive, Shaker-related $\mathrm{K}^{+}$channels; our immunohistochemistry confirms that MNTB neurons express Kv1.1, Kv1.2, and Kv1.6 subunits. We used subunit-specific toxins to separate $I_{\mathrm{LT}}$ into two components, each contributing approximately one-half of the total low-threshold current: (1) $I_{\text {LTS }}$, a tityustoxin-K $\alpha$ sensitive current (TsTX) (known to block Kv1.2 containing channels), and (2) I LTR , an TsTX-resistant current. Both components were sensitive to the Kv1.1-specific toxin dendrotoxin-K and were insensitive to tetraethylammonium (1 mm). This pharmacological profile excludes homomeric Kv1.1 or Kv1.2 channels and is consistent with $I_{\text {LTS }}$ channels being Kv1.1/Kv1.2 heteromers, whereas $I_{\text {LTR }}$ channels are probably Kv1.1/Kv1.6 heteromers. Although they have similar kinetic properties, ILTS is critical for generating the phenotypic single AP response of MNTB neurons. Immunohistochemistry confirms that Kv1.1 and Kv1.2 ( $I_{\text {LTS }}$ channels), but not Kv1.6, are concentrated in the first $20 \mu \mathrm{m}$ of MNTB axons. Our results show that heteromeric channels containing Kv1.2 subunits govern AP firing and suggest that their localization at the initial segment of MNTB axons can explain their dominance of AP firing behavior.

Key words: medial nucleus of the trapezoid body; MNTB; low-threshold potassium currents; Kv1.1; KCNA1; Kv1.2; KCNA2; Kv1.6; KCNA6; dendrotoxin; DTX; tityustoxin; TsTX; sound localization; auditory system; channel localization; heteromeric assembly
The seven members of the Shaker-related $\mathrm{K}^{+}$channel family (Kv1.1-Kv1.7) generate voltage-dependent outward currents, which regulate action potential (AP) threshold, waveform, and pacemaker activity in nerve and muscle (Hille, 2001). When expressed as homomeric channels, most have "delayed rectifier" properties (Kv1.1, Kv1.2, Kv1.5, and Kv1.6), with others exhibiting fairly rapid inactivation (Kv1.3, Kv1.4, and Kv1.7). They are widely expressed in axonal, dendritic, and somatic compartments in the brain (Wang et al., 1994; Coetzee et al., 1999), with the exception of Kv1.7 (Kalman et al., 1998; Kashuba et al., 2001). Functional channels contain four $\mathrm{Kv} \alpha$ subunits and up to four $\mathrm{Kv} \beta$ subunits (Xu et al., 1998); heteromers are common (Isacoff et al., 1990; Ruppersberg et al., 1990), but particular subunit combinations are favored in vivo (Koch et al., 1997; Shamotienko et al., 1997; Koschak et al., 1998; Coleman et al., 1999; Wang et al., 1999b).

The medial nucleus of the trapezoid body (MNTB) expresses low-threshold $\mathrm{K}^{+}$currents $\left(I_{\mathrm{LT}}\right)$, which are blocked by dendrotoxin-I (DTX-I), suggesting mediation by channels containing Kv1.1, Kv1.2, and/or Kv1.6 (Brew and Forsythe, 1995). In addition, high-threshold potassium channels, including Kv3.1, are expressed, which minimize AP duration (Brew and Forsythe,

\footnotetext{
Received April 15, 2002; revised May 17, 2002; accepted May 21, 2002.

This work was supported by the Wellcome Trust and the Medical Research Council. P.D.D. is a Wellcome Trust Prize PhD student. We thank Drs. Margaret Barnes-Davies, Brian Billups, and Brian Robertson for critically reading this manuscript.

Correspondence should be addressed to Prof. I. D. Forsythe, Department of Cell Physiology and Pharmacology, University of Leicester, P.O. Box 138, Leicester, LE1 9HN, UK. E-mail: idf@le.ac.uk.

Copyright (C) 2002 Society for Neuroscience $0270-6474 / 02 / 226953-09 \$ 15.00 / 0$
}

1995; Wang et al., 1998; Rudy and McBain, 2001). The MNTB forms an inverting relay in the binaural auditory pathway, in which AP timing is crucial to encoding interaural timing and level differences associated with sound source localization (Park et al., 1996; Trussell, 1999). The $\mathrm{K}^{+}$currents and specializations such as a large synapse (calyx of Held) generating fast glutamatergic EPSCs (which ensure minimal latency fluctuation and secure AP generation) (Barnes-Davies and Forsythe, 1995) preserve timing by enabling MNTB neurons to faithfully follow the pattern of presynaptic activity, even during high-frequency transmission (up to $800 \mathrm{~Hz}$ ) (Taschenberger and von Gersdorff, 2000). Dendrotoxin-sensitive currents $\left(I_{\mathrm{D}}\right)$, which are similar to $I_{\mathrm{LT}}$ in the MNTB, are present in hippocampal and cortical pyramidal neurons (Wu and Barish, 1992; Bekkers and Delaney, 2001) in which they modulate excitability by regulating AP firing threshold.

Specific toxins for Kv1 channels have been isolated from scorpion and snake venom (Tytgat et al., 1999; Harvey, 2001). DTX-I (from Dendroaspis polylepis polylepis) will block low-threshold $\mathrm{K}^{+}$ channels containing Kv1.1, Kv1.2, or Kv1.6 subunits, but more specific toxins are available. Dendrotoxin-K (DTX-K) specifically blocks Kv1.1-containing channels (Robertson et al., 1996; Wang et al., 1999b), tityustoxin-K $\alpha$ (TsTX) (from Tityus serrulatus) blocks most Kv1.2-containing channels (Matteson and Blaustein, 1997; Hopkins, 1998), and noxiustoxin (NTX) (from Centruriodes noxius) blocks channels containing Kv1.2, Kv1.3, or Kv1.7 (Grissmer et al., 1994; Kalman et al., 1998). Because only one subunit is required for the toxin to bind, they block most heteromeric channels containing at least one toxin-sensitive subunit (Hopkins, 1998). We exploited these toxins to examine the composition and 
relative importance of Kv subunits in generating $I_{\mathrm{LT}}$ channels in MNTB neurons. We find that $I_{\mathrm{LT}}$ has two components, distinguishable by their sensitivity to tityustoxin-K $\alpha$, and show that Kv1.2-containing channels are dominant in determining the unitary AP firing of MNTB neurons.

\section{MATERIALS AND METHODS}

Brain slice preparation. Brain slices were prepared using methods described previously (Barnes-Davies and Forsythe, 1995). Briefly, Lister hooded rats ( $8-14 \mathrm{~d}$ old) were killed by decapitation, and the brain was removed in ice-cold low sodium artificial CSF (aCSF) (see below). The brain was placed ventral side down and cut just posterior to the cerebellum at an angle of $\sim 20^{\circ}$ to the vertical, removing the spinal cord. The hemispheres were removed with a vertical cut, and the brainstem was mounted severed caudal surface down to the stage of a DTK-1000 slicer (Dosaka, Kyoto, Japan). Six to eight transverse slices 100 - to $150-\mu \mathrm{m}-$ thick were cut from the region of the brainstem containing the MNTB. The slices were incubated at $37^{\circ} \mathrm{C}$ for $1 \mathrm{hr}$ in normal aCSF (see below) and then allowed to cool to room temperature.

Immunohistochemistry. Brainstems from Lister hooded rats (postnatal day 9) were transferred from aCSF to Tissue Tek (Sakura, Tokyo, Japan) and frozen using hexane and dry ice. Transverse cryostat sections (20 $\mu \mathrm{m})$ were mounted on subbed slides. Sections were fixed in $2 \%$ paraformaldehyde solution for $10 \mathrm{~min}$. After washing for $15 \mathrm{~min}$ (1\% PBS), sections were permeabilized in PBS and $10 \%$ goat serum (Dako, High Wycombe, UK) and $0.5 \%$ Triton X-100 for $1 \mathrm{hr}$. Sections were washed in $1 \%$ PBS (twice for $15 \mathrm{~min}$ each), and primary antibodies (Kv1.1, Kv1.2, Kv1.4, Kv1.5, and Kv1.6) were applied at a concentration of 1:100 and then incubated overnight at $4^{\circ} \mathrm{C}$. Sections were washed in $1 \%$ PBS (six times for $10 \mathrm{~min}$ each), incubated for $2 \mathrm{hr}$ with a FITC secondary antibody (1:1000) at room temperature, and then washed again in 1\% PBS (twice for $15 \mathrm{~min}$ each). Colocalization studies followed the immunohistochemical protocol described previously. Kv1.1 and Kv1.2 primary antibodies (raised in rabbit and mouse, respectively) were applied at the same dilutions. Secondary antibodies (FITC at 1:500 and Texas Red at 1:250) were applied together. Slides were mounted using Citifluor antifade mountant. Results were visualized using a Nikon (Tokyo, Japan) epifluorescent microscope, recorded with a Cohu (San Diego, CA) CCD camera with no automatic gain control, and analyzed using NIH Image. Pixel intensities of the immunoreactivity from Kv1 antibodies were calculated by measuring the mean intensity over an area of $4800 \mathrm{\mu m}^{2}$ covering the MNTB. To account for nonspecific secondary antibody fluorescence, background immunofluorescence was measured from control sections in which only secondary antibody had been applied, and this was subtracted from test data. Blocking peptide controls were used to assess nonspecific binding of primary antibodies (see Fig. $1 G$ ). In these experiments, blocking peptide was incubated with the primary antibody $(5: 1)$ for $1 \mathrm{hr}$ before application. No reliable Kv1.3 antibody was available, but, as shown below, electrophysiological and pharmacological evidence indicated that this subunit was not present. Kv1.7 expression was not examined because this subunit is not expressed in the brain (Kalman et al., 1998; Kashuba et al., 2001). Subcellular localization was investigated by examining immunofluorescence using an Olympus Optical (Tokyo, Japan) Fluoview confocal microscope (IX70) with a $60 \times$, numerical aperture (NA) 1.4 objective.

Electrophysiological recordings. For recording, one slice was placed in a Peltier controlled environmental chamber mounted on the stage of an upright E600FN microscope (Nikon) fitted with differential interference contrast optics and a $60 \times($ NA 1.00$)$ water immersion objective (Nikon). The environmental chamber was continuously perfused with normal aCSF $\left(\sim 1 \mathrm{ml} / \mathrm{min}, 25^{\circ} \mathrm{C}\right)$. Whole-cell patch recordings were made from visually identified MNTB neurons using an Optopatch amplifier (Cairn, Faversham, UK). This patch-clamp amplifier has an optically coupled head stage permitting both voltage-clamp and current-clamp control, allowing accurate action potential measurements. Patch pipettes with resistances of 2.5-4 $\mathrm{M} \Omega$ were pulled from thick-walled borosilicate glass (GC150F-7.5; Harvard Apparatus, Edenbridge, UK) and filled with intracellular patch solution (see below). Series resistances were $9.3 \pm 0.6$ $\mathrm{M} \Omega(n=21)$ and were routinely compensated by $70 \%$. Recordings in which the series resistances changed by more than $\pm 2 \mathrm{M} \Omega$ during the course of an experiment were excluded from analysis. Currents were evoked by voltage steps up to $0 \mathrm{mV}$; this enabled us to investigate low-threshold currents without introducing series resistance errors asso- ciated with large currents. Stated voltages exclude a $-7 \mathrm{mV}$ junction potential.

Data acquisition and analysis. Data were acquired via a CED1401 interface using Patch v6.39 software (Cambridge Electronics Design, Cambridge, UK) running on a PIII 550 computer. Data were filtered at $2 \mathrm{kHz}$ and digitized at between 5 and $10 \mathrm{kHz}$. Unless stated otherwise, current-voltage $(I-V)$ relationships were produced using the current amplitude measured at $10 \mathrm{msec}$ into the voltage step. Leak currents were not subtracted from the current records, but, for presentation purposes, the leak was subtracted from the data points in current-voltage relationships (as estimated from a linear fit over a voltage range between -90 and $-75 \mathrm{mV}$, in the presence of ZD7288 to block $\left.I_{\mathrm{H}}\right)$. Half-inactivation was estimated using a fractional Boltzmann equation: $I=I_{\max }(1-$
fraction $) /\left(1+\mathrm{e}^{\left(V-V_{1 / 2) / K}\right)}\right.$. Averaged data are expressed as mean \pm SEM.

Solutions and toxins. All chemicals were obtained from Sigma (St. Louis, MO) unless otherwise stated. The low $\mathrm{Na}^{+}$aCSF used for slicing contained the following (in $\mathrm{mM}$ ): 250 sucrose, $2.5 \mathrm{KCl}, 10$ glucose, 1.25 $\mathrm{NaH}_{2} \mathrm{PO}_{4}, 26 \mathrm{NaHCO}_{3}, 2$ sodium pyruvate, 3 myo-inositol, 0.5 ascorbic acid, $0.1 \mathrm{CaCl}_{2}$, and $4 \mathrm{MgCl}_{2}$. Normal aCSF contained the following (in mM): $125 \mathrm{NaCl}, 2.5 \mathrm{KCl}, 10$ glucose, $1.25 \mathrm{NaH}_{2} \mathrm{PO}_{4}, 26 \mathrm{NaHCO}_{3}, 2$ sodium pyruvate, 3 myo-inositol, 0.5 ascorbic acid, $2 \mathrm{CaCl}_{2}$, and $1 \mathrm{MgCl}_{2}$. For data recording, extracellular $\mathrm{CaCl}_{2}$ and $\mathrm{MgCl}_{2}$ concentrations were changed to 0.5 and $2.5 \mathrm{~mm}$, respectively; to minimize calcium-activated potassium currents, ZD7288 (10 $\mu \mathrm{M}$; Tocris Cookson, Bristol, UK) was added to block $I_{\mathrm{H}}$. Tetrodotoxin (TTX) (1 $\mu \mathrm{M}$; Latoxan, Valence, France) was used to block the voltage-gated $\mathrm{Na}^{+}$currents in voltageclamp experiments. External solutions were gassed with $95 \% \quad \mathrm{O}_{2}-5 \%$ $\mathrm{CO}_{2}$ to give a $\mathrm{pH}$ of 7.4. Intracellular patch solution contained the following (in $\mathrm{mM}$ ): $97.5 \mathrm{~K}$-gluconate, $32.5 \mathrm{KCl}, 10 \mathrm{HEPES}, 5 \mathrm{EGTA}$, and $1 \mathrm{MgCl}_{2}$, pH 7.2 with KOH. Toxins were applied through independent, dedicated perfusion lines to avoid contamination of control solutions. Toxins and antibodies were obtained from the following sources: DTX-I, NTX, and Kv1.1, Kv1.2, Kv1.4, Kv1.5, and Kv1.6 antibodies were from Alomone Labs (Jerusalem, Israel); additional Kv1.2 and Kv1.6 antibodies were from Upstate Biotechnology (Lake Placid, NY); TsTX was from Peptide Institute (Osaka, Japan); CP-339,818 was from Tocris Cookson; and DTX-K was a kind gift from Brian Robertson (Imperial College, London, UK).

\section{RESULTS}

\section{Expression of Kv1 subunits in the MNTB}

Immunohistochemical labeling was used to determine Kv1 subunit expression in the MNTB. Primary antibodies for Kv1.1, Kv1.2, Kv1.4, Kv1.5, and Kv1.6 were applied to rat brainstem sections (transverse plane, $20 \mu \mathrm{m}$ thick). The immunofluorescence was subtracted from background (Fig. $1 F$ ), and average data from three animals is plotted in the bar chart (Fig. 1G). High levels of immunoreactivity were detected for Kv1.1, Kv1.2, and Kv1.6, whereas only low levels were present for Kv1.4 and Kv1.5 (Fig. $1 A-E$ ). The immunoreactivity of Kv1.4 and Kv1.5 were not significantly different from that when blocking peptide was applied ( $p>0.5$; paired $t$ test). This suggests that Kv1.4 and Kv1.5 immunoreactivity was attributable to nonspecific binding of the primary antibody. Although the immunoreactivity measured will include membrane and cytoplasmic staining, these data suggest that $\mathrm{Kv1.1}, \mathrm{Kv1.2}$, and Kv1.6 are expressed in the MNTB, whereas Kv1.4 and Kv1.5 are absent.

\section{DTX-I blocks the low-threshold current}

Voltage-gated currents were evoked by voltage steps ranging from -90 to $0 \mathrm{mV}$ in $5 \mathrm{mV}$ increments (but for the purposes of clarity, only alternate traces are shown in the figures). Each test step was preceded by a $750 \mathrm{msec}$ prepulse to $-100 \mathrm{mV}$ (Fig. $2 E$ ) to remove resting voltage-dependent inactivation or a prepulse to $-30 \mathrm{mV}$ (Fig. $2 E$, dashed line) to induce inactivation (Brew and Forsythe, 1995; Wang et al., 1998). Outward potassium currents began to activate at potentials more positive than $-70 \mathrm{mV}$ (Fig. 2A,C), activated rapidly, peaked at 10 msec (measured on a step to $-30 \mathrm{mV}$ ), and then partially 

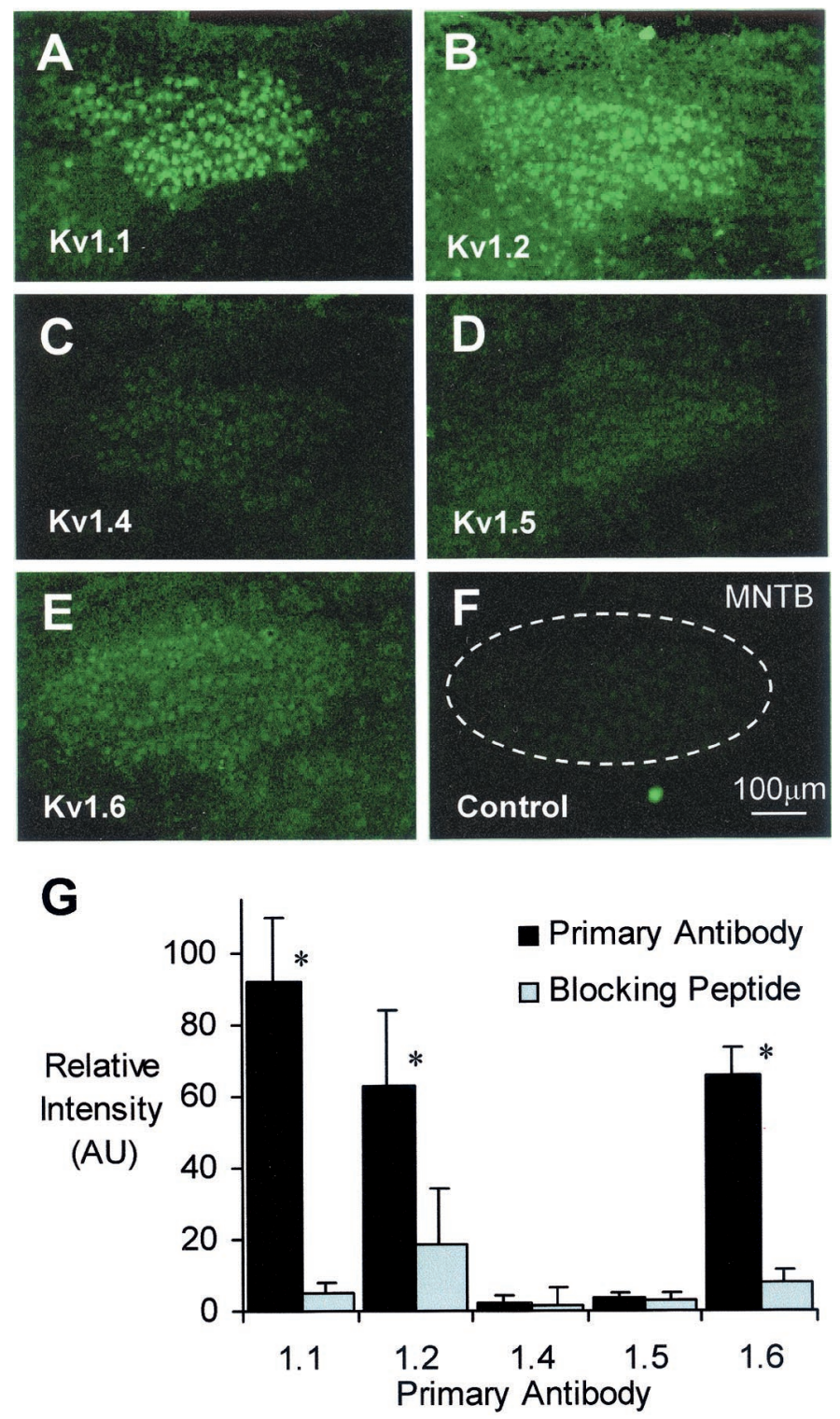

Figure 1. Immunoreactivity for Kv1.1, Kv1.2, and Kv1.6 is present in the MNTB. Pixel intensities for Kv1.1 were greater than for Kv1.2 and Kv1.6 (measured over an area of $4800 \mu \mathrm{m}^{2}$ ). $A-E$, In each case, an example low-power $(10 \times$ objective) image of the MNTB is shown. The primary antibody used is indicated in the bottom left of each panel. F, Control image denoting background fluorescence represents secondary antibody fluorescence with the primary antibody substituted for $10 \%$ goat serum. $G$, Mean immunofluorescence above background from three animals. Kv1.1, Kv1.2, and Kv1.6 immunofluorescence was significantly higher than when blocking peptide was incubated with the primary antibody $\left({ }^{*} p<0.05\right.$; paired $t$ test). Immunofluorescence for Kv1.4 and Kv1.5 was not significantly different from that in the presence of blocking peptide, suggesting that the measured fluorescence was attributable to nonspecific binding of these primary antibodies. $A U$, Arbitrary units. Scale bar, $100 \mu \mathrm{m}$.

inactivated. The magnitude of the outward currents evoked by steps to -45 and $0 \mathrm{mV}$ was $0.60 \pm 0.05$ and $4.8 \pm 0.4 \mathrm{nA}$, respectively $(n=21)$. Previously, Brew and Forsythe (1995) demonstrated that DTX-I, which specifically blocks channels containing $\mathrm{Kv} 1.1, \mathrm{Kv} 1.2$, or $\mathrm{Kv} 1.6$ ( $\mathrm{IC}_{50}$ of $3 \mathrm{~nm}$ for homomers) (Hopkins, 1998), blocks the low-threshold current in MNTB neurons. In our experiments, $100 \mathrm{~nm}$ DTX-I blocked $82 \pm 5 \%$ of the current measured at $-45 \mathrm{mV}(n=4)$ (Fig. $2 C, D, F)$. The

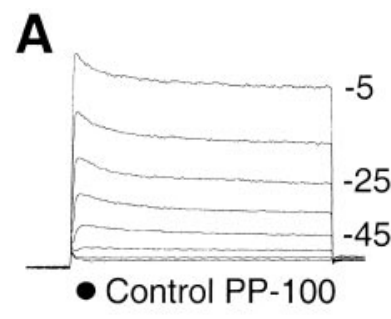

B
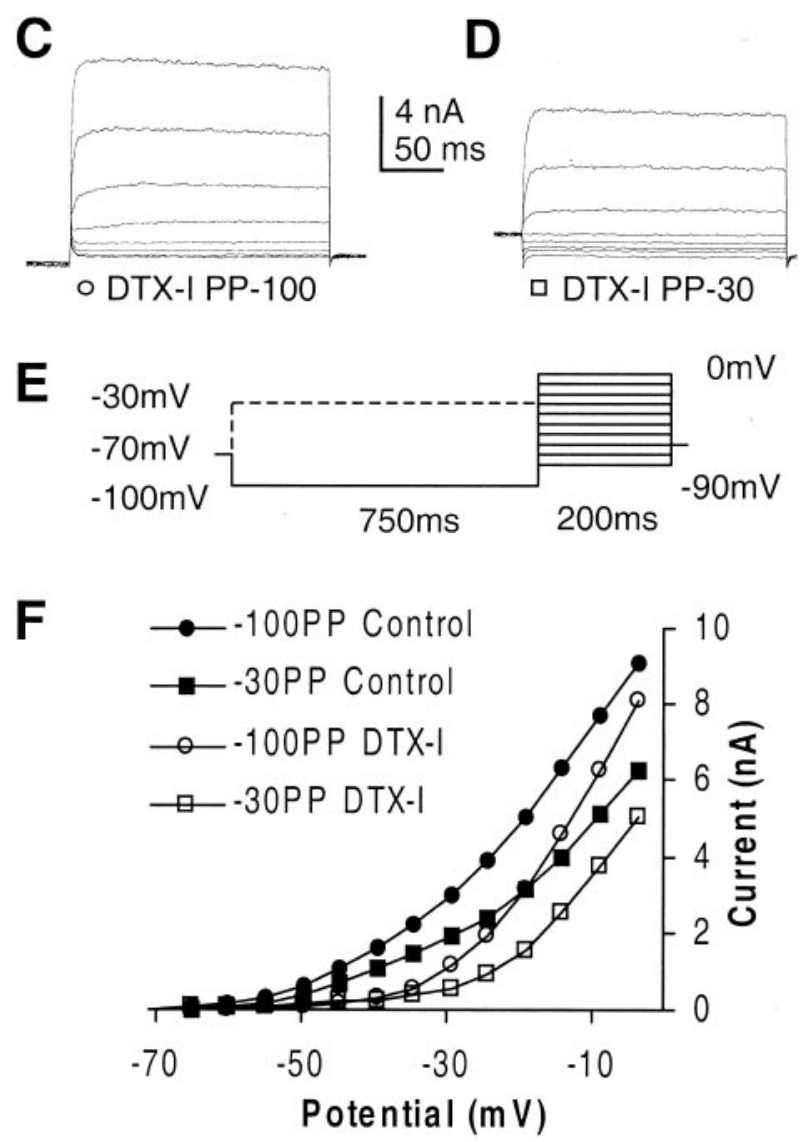

Figure 2. DTX-I, a potent blocker of Kv1.1, Kv1.2, and Kv1.6, blocks the low-threshold component $\left(I_{\mathrm{LT}}\right)$ of outward currents in MNTB neurons. Traces show $I-V$ relationships for the same neuron after a $750 \mathrm{msec}$ prepulse $(P P)$ to either $-100 \mathrm{mV}(A, C)$ or $-30 \mathrm{mV}(B, D)$. Voltage protocols are show in $E$. At the end of each protocol, the cell returned to a holding potential of $-70 \mathrm{mV}$; current traces are aligned to the current at this potential. $A$, Control responses after a $-100 \mathrm{mV}$ prepulse. $B, \mathrm{~A}$ $-30 \mathrm{mV}$ prepulse inactivates the transient portion of the outward current. $C$, Currents after a $-100 \mathrm{mV}$ prepulse in the presence of $100 \mathrm{~nm}$ DTX-I. DTX-I blocks the low-threshold current, so that outward current is now seen only at potentials positive to $-50 \mathrm{mV}$. $D$, Currents after a $-30 \mathrm{mV}$ prepulse in the presence of $100 \mathrm{~nm}$ DTX-I. E, Voltage protocols applied. Test steps $(200 \mathrm{msec})$ to potentials between -90 and $-5 \mathrm{mV}$ were preceded by prepulses to $-100 \mathrm{mV}$ (solid line) or $-30 \mathrm{mV}$ (dashed line). $F, I-V$ relationships for $A-D$, with the linear leak subtracted. Data is presented from one neuron, with similar results observed in three neurons.

DTX-I-insensitive current at $-45 \mathrm{mV}$ is presumably the highthreshold current, which begins to activate at these potentials (Brew and Forsythe, 1995; Macica and Kaczmarek, 2001). DTX-I block of the low-threshold current can be clearly seen in the first four traces after the prepulse to $-30 \mathrm{mV}$ (Fig. $2 B, D)$. $I_{\mathrm{LT}}$ exhibits some partial inactivation (Brew and Forsythe, 1995), seen in Figure 2, compare $A$ with $C$. 

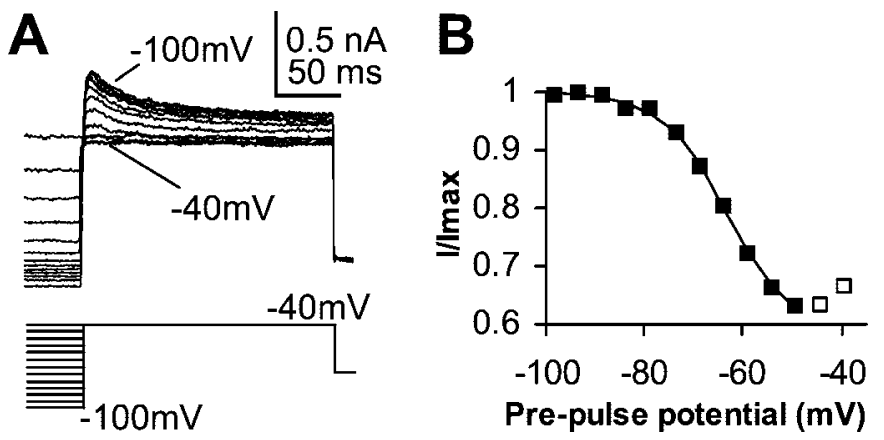

Figure 3. Half-inactivation of the low-threshold current. $A$, The current response to a test step at $-40 \mathrm{mV}$, after $750 \mathrm{msec}$ prepulses to potentials ranging from -100 to $-40 \mathrm{mV} . B, I / I_{\max }$ is plotted against prepulse potential. The inactivation of the low-threshold current was well fit by a fractional Boltzmann, with a $V_{1 / 2}$ of $-63 \pm 3 \mathrm{mV}$, a $K$ value of $7.9 \pm 0.8$ $\mathrm{mV}$, and a fraction of $0.40 \pm 0.01(n=4)$. The Boltzmann fit is to potentials from -100 to $-50 \mathrm{mV}$ (filled squares). At potentials more positive than $-50 \mathrm{mV}$, the high-threshold current begins to activate (open squares).

\section{Inactivation of $I_{\mathrm{LT}}$}

$I_{\mathrm{LT}}$ in MNTB neurons has a partially inactivating component (Fig. 2). We investigated the half-inactivation potential of $I_{\mathrm{LT}}$ by applying $750 \mathrm{msec}$ prepulses to potentials between -100 and $-40 \mathrm{mV}$, followed by a test step to $-40 \mathrm{mV}$, as shown in Figure $3 A$. The peak current during the test step was measured and plotted as a partial Boltzmann (Fig. $3 B$ ). Half-inactivation of $I_{\mathrm{LT}}$ was determined empirically to be at approximately $-50 \mathrm{mV}$, but estimation of the true $V_{1 / 2}$ was not possible because $I_{\mathrm{LT}}$ inactivates only partially (40\%) and overlaps with activation of highthreshold currents (Fig. 3B).

\section{Block of low-threshold current by subunit-specific toxins}

To further characterize the low-threshold current and to provide clues to the channel subunit composition, we used toxins specific for one or two Kv1 subunits. DTX-K (100 nM), which blocks channels containing Kv1.1 subunits ( $\mathrm{IC}_{50}$ of $2.5 \mathrm{~nm}$ for homomers) (Robertson et al., 1996; Wang et al., 1999a), blocked $90 \pm 4 \%$ of the low-threshold current in MNTB neurons (measured at -45 $\mathrm{mV} ; n=4$ ) (Fig. 4A,D). NTX blocks channels containing Kv1.2,

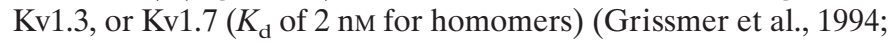
Kalman et al., 1998). Noxiustoxin (100 nM) only partially blocked the low-threshold current (Fig. $4 B$ ), blocking $48 \pm 5 \%$ of the current at $-45 \mathrm{mV}(n=3)$ (Fig. $4 B, D)$. TsTX (100 nM) blocks channels containing $\mathrm{Kv} 1.2$ ( $\mathrm{IC}_{50}$ of $0.55 \mathrm{~nm}$ for homomers) (Hopkins, 1998) and blocked $48 \pm 4 \%$ of the current at $-45 \mathrm{mV}(n=$ 7) (Fig. $4 C, D)$. The toxin block data suggests that there are at least two components to the low-threshold current. One component is blocked by TsTX and NTX and therefore presumably contains at least one Kv1.2 subunit; we termed this component $I_{\mathrm{LTS}}$, for a low-threshold tityustoxin-sensitive current. DTX-K blocks both components of the low-threshold current, suggesting that each contains at least one Kv1.1 subunit. The current blocked by DTX-K but resistant to TsTX we termed $I_{\text {LTR }}$, for lowthreshold tityustoxin-resistant current. To investigate whether Kv1.3 subunits contribute to $I_{\text {LTS }}$, we used CP-339,818, which blocks Kv1.3 and Kv1.4 ( $\mathrm{IC}_{50}$ of $0.23 \mu \mathrm{M}$ for Kv1.3 homomers) (Nguyen et al., 1996; Jager et al., 1998). CP-339,818 (1 $\mu \mathrm{M})$ had no effect on the current measured at $-45 \mathrm{mV}(n=3$; data not shown), suggesting that $I_{\text {LTS }}$ channels do not contain Kv1.3 subunits.

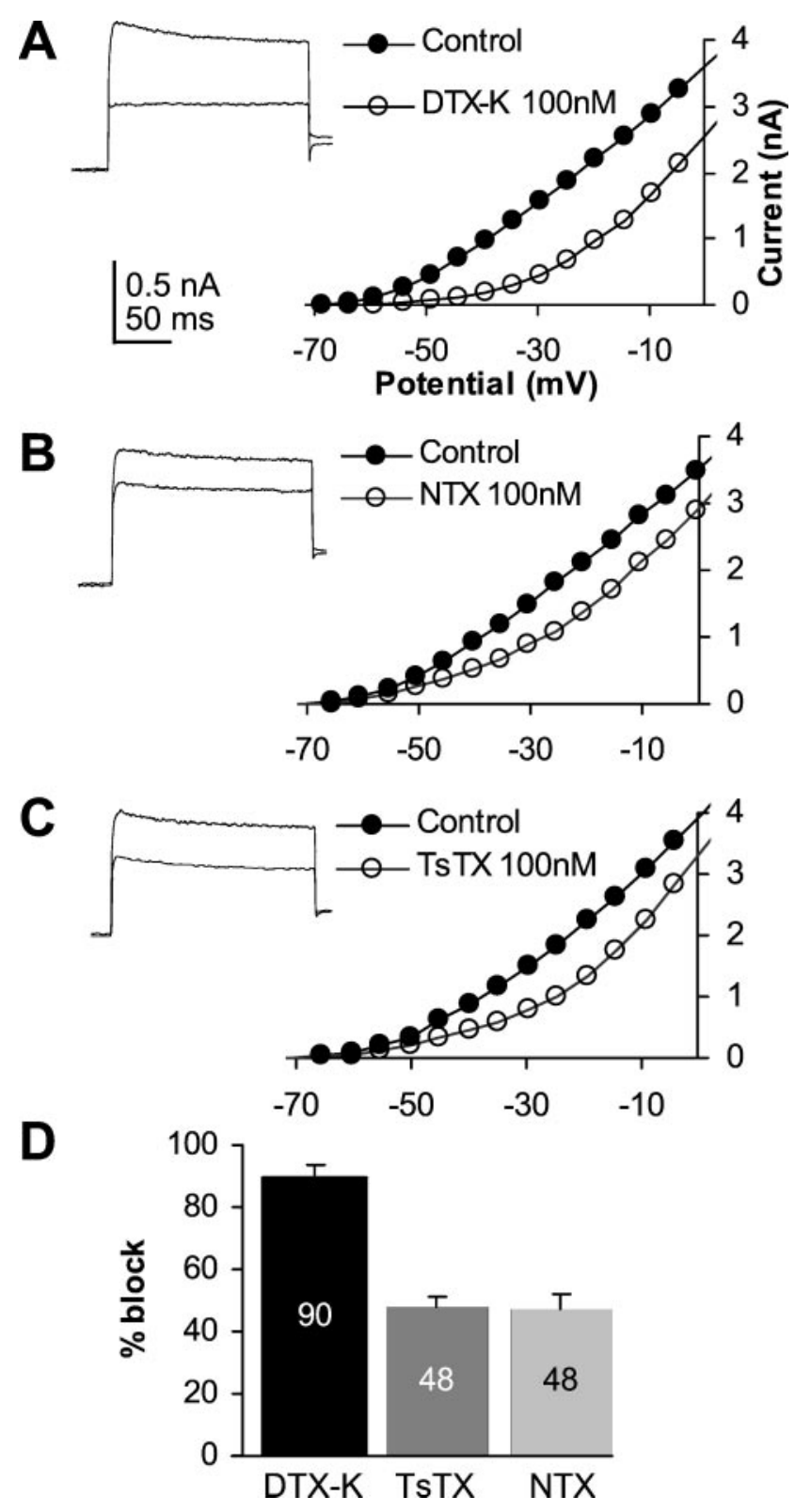

Figure 4. Action of subunit-specific toxins on $I_{\mathrm{LT}}$. DTX-K, a potent blocker of Kv1.1, blocks all of the low-threshold current, whereas TsTX (blocks Kv1.2) and NTX (blocks Kv1.2-, Kv1.3-, or Kv1.7-containing channels) only block half of $I_{\mathrm{LT}}$. Example data are shown for three different cells. The respective inset traces are the current activated by a step to $-45 \mathrm{mV}$ after a $750 \mathrm{msec}$ prepulse to $-100 \mathrm{mV}$. The top trace is a control, and the bottom trace is the current in $100 \mathrm{~nm}$ toxin. $I-V$ relationships are shown after linear leak subtraction, but example traces are not leak subtracted. $A$, DTX-K blocks $90 \pm 4 \%$ of the current at -45 $\mathrm{mV}(n=4)$. The high-threshold current, seen in the presence of DTX-K (open symbols), activates at approximately $-45 \mathrm{mV} . B$, NTX blocks $48 \pm$ $5 \%$ of the current at $-45 \mathrm{mV}(n=3)$. $C$, TsTX blocks $48 \pm 4 \%$ of the current at $-45 \mathrm{mV}(n=7) . D$, Bar chart of the percentage of the current at $-45 \mathrm{mV}$ blocked by $100 \mathrm{~nm}$ DTX-K $(n=4)$, NTX $(n=3)$, and TsTX $(n=7)$.

\section{$I_{\text {LTS }}$ is of dominant functional relevance}

MNTB neurons characteristically fire a single action potential in response to sustained current injection or synaptic stimulation (Brew and Forsythe, 1995). The low-threshold potassium current is crucial in maintaining this response because, when it is blocked, a train of APs is fired. In control conditions, single APs were 


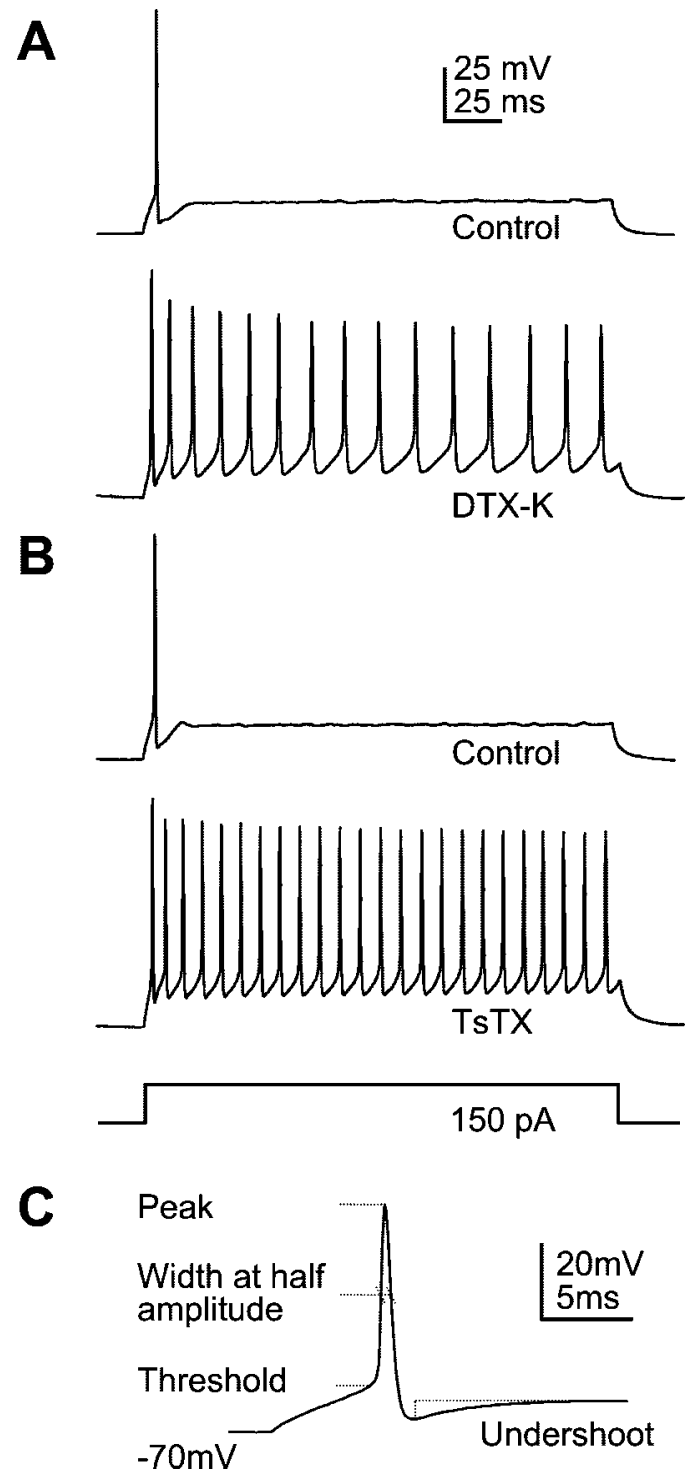

Figure 5. DTX-K and TsTX both cause MNTB neurons to fire multiple action potentials. $A$, Characteristic single action potential in response to sustained depolarization in control conditions. In $100 \mathrm{~nm}$ DTX-K, which blocks the low-threshold current, the same cell fires multiple action potentials. $B$, In $100 \mathrm{~nm}$ TsTX, which blocks one component of the low-threshold current $\left(I_{\text {LTS }}\right)$, MNTB neurons also fire multiple action potentials. In this example, more APs are fired in TsTX than in the example shown for DTX-K. However, the mean number of APs fired was $18 \pm 4$ for both DTX-K and TsTX (during a $200 \mathrm{msec}$ step of $200 \mathrm{pA} ; n=$ 3 for each toxin). Bottom trace shows current step time course for $A$ and $B$. $C$, An action potential showing points of measurement for quantification presented in Results and Table 1. Representative traces are shown, although similar results were observed in three neurons.

evoked in each of six cells by current injections in $50 \mathrm{pA}$ increments over a range of $0-350 \mathrm{pA}$ (Fig. 5A, Table 1). The threshold for AP firing was reached with current injection above $100 \mathrm{pA}$ in all cells, but, in some neurons, threshold was as high as $200 \mathrm{pA}$ $(n=6)$. AP characteristics were measured from six neurons during a $200 \mathrm{pA}$ current injection from a membrane potential of $-70 \mathrm{mV}$ (Table 1). Each AP was followed by a shallow afterhyperpolarization with an undershoot of $-8.0 \pm 0.6 \mathrm{mV}(n=6)$ (Fig. 5C). In the presence of $100 \mathrm{~nm}$ DTX-K, which blocks both low-threshold currents ( $I_{\text {LTS }}$ and $\left.I_{\text {LTR }}\right)$, MNTB neurons fired
Table 1. Action potential characteristics

\begin{tabular}{lllll} 
& $n$ & $\begin{array}{l}\text { Threshold } \\
(\mathrm{mV})\end{array}$ & $\begin{array}{l}\text { Peak } \\
(\mathrm{mV})\end{array}$ & $\begin{array}{l}\text { Width at } \\
\text { half-amplitude } \\
(\mu \mathrm{sec})\end{array}$ \\
\hline Control & 6 & $-50 \pm 2$ & $37 \pm 2$ & $575 \pm 28$ \\
TsTX & 3 & $-54 \pm 2$ & $37 \pm 5$ & $567 \pm 33$ \\
DTX-K & 3 & $-54 \pm 1$ & $39 \pm 8$ & $550 \pm 29$ \\
\hline
\end{tabular}

trains of APs (Fig. $5 A$ ); the mean number of APs fired during a $200 \mathrm{msec}$ step of $200 \mathrm{pA}$ was $18 \pm 4(n=3)$. Interestingly, $100 \mathrm{~nm}$ TsTX, which blocks only $I_{\text {LTS }}$, also caused the MNTB neuron to fire trains of APs at a similar rate (Fig. $5 B$ ). The mean number of APs fired during a $200 \mathrm{msec}$ step of $200 \mathrm{pA}$ in TsTX was $18 \pm 4$ $(n=3)$. Although in the example record in Figure $5 A$ fewer APs were seen in DTX-K, on average, the number of APs was the same in TsTX and DTX-K. DTX-K or TsTX had no effect on the waveform of the first AP compared with control APs (Table 1). Subsequent APs in the presence of DTX-K had the same characteristics as those in TsTX, suggesting that $I_{\text {LTR }}$ has little effect on these parameters. Because multiple APs were not generated under control conditions, we were not able to assess whether $I_{\text {LTS }}$ affects the waveform of subsequent APs. In TsTX and DTX-K, firing threshold was lower than control (Table 1), being reached with current injection of $<50 \mathrm{pA}$ in some neurons and achieved in all cells with injection of $100 \mathrm{pA}(n=6)$.

Because $I_{\text {LTS }}$ accounts for half of the low-threshold current, it is important to determine whether the effect of TsTX on AP firing is a specific consequence of the $I_{\text {LTS }}$ component or merely attributable to a general block of half the low-threshold current. To distinguish between these possibilities, we compared the AP response after half-inactivation of all low-threshold $\mathrm{K}^{+}$currents with the response in TsTX. $I_{\mathrm{LTR}}$ and $I_{\mathrm{LTS}}$ will be equally and maximally inactivated (by $40 \%$ of their peak amplitude) (Fig. 3) at a membrane potential of $-50 \mathrm{mV}$.

The effect of half-inactivation of low-threshold currents on AP firing was investigated in current clamp by depolarizing from a membrane potential of $-50 \mathrm{mV}$ (as opposed to $-70 \mathrm{mV}$ for control data). The mean number of action potentials observed in response to a $350 \mathrm{pA}$ current injection from $-50 \mathrm{mV}$ was $6 \pm 2$ $(n=6)$ compared with $26 \pm 5(n=3)$ with TsTX from $-70 \mathrm{mV}$ (Fig. 6A). The number of APs generated for a given current step is plotted in Figure $6 A$ for three conditions: control (APs evoked from $-70 \mathrm{mV}$ ); after half-inactivation (at a membrane potential of $-50 \mathrm{mV}$ ); and after application of TsTX (from $-70 \mathrm{mV}$ ). The same data are also plotted as the number of APs against the absolute membrane potential in Figure $6 B$ to demonstrate that the difference in AP firing is not attributable to changes in membrane conductance. For current steps over $250 \mathrm{pA}$, there are significantly more APs in TsTX compared with half-inactivating $I_{\mathrm{LT}}$ (at a membrane potential of $-50 \mathrm{mV}$ ) as shown in Figure $6, A$ and $C(p<0.05$; unpaired $t$ test $)$. These data show that half-block of $I_{\mathrm{LT}}$ by TsTX gives a different functional response than halfblock of $I_{\mathrm{LT}}$ through inactivation. Because TsTX is specifically blocking only those channels contributing to $I_{\text {LTS }}$, this strongly implies that $I_{\text {LTS }}$ has the dominant functional impact on AP firing in MNTB neurons. The fact that $\mathrm{I}_{L T S}$ is $40 \%$ inactivated at $-50 \mathrm{mV}$ explains why more than one AP can be generated from this potential (Fig. 6). Depolarizing the membrane to $-50 \mathrm{mV}$ will result in some sodium channel inactivation; however, this is 

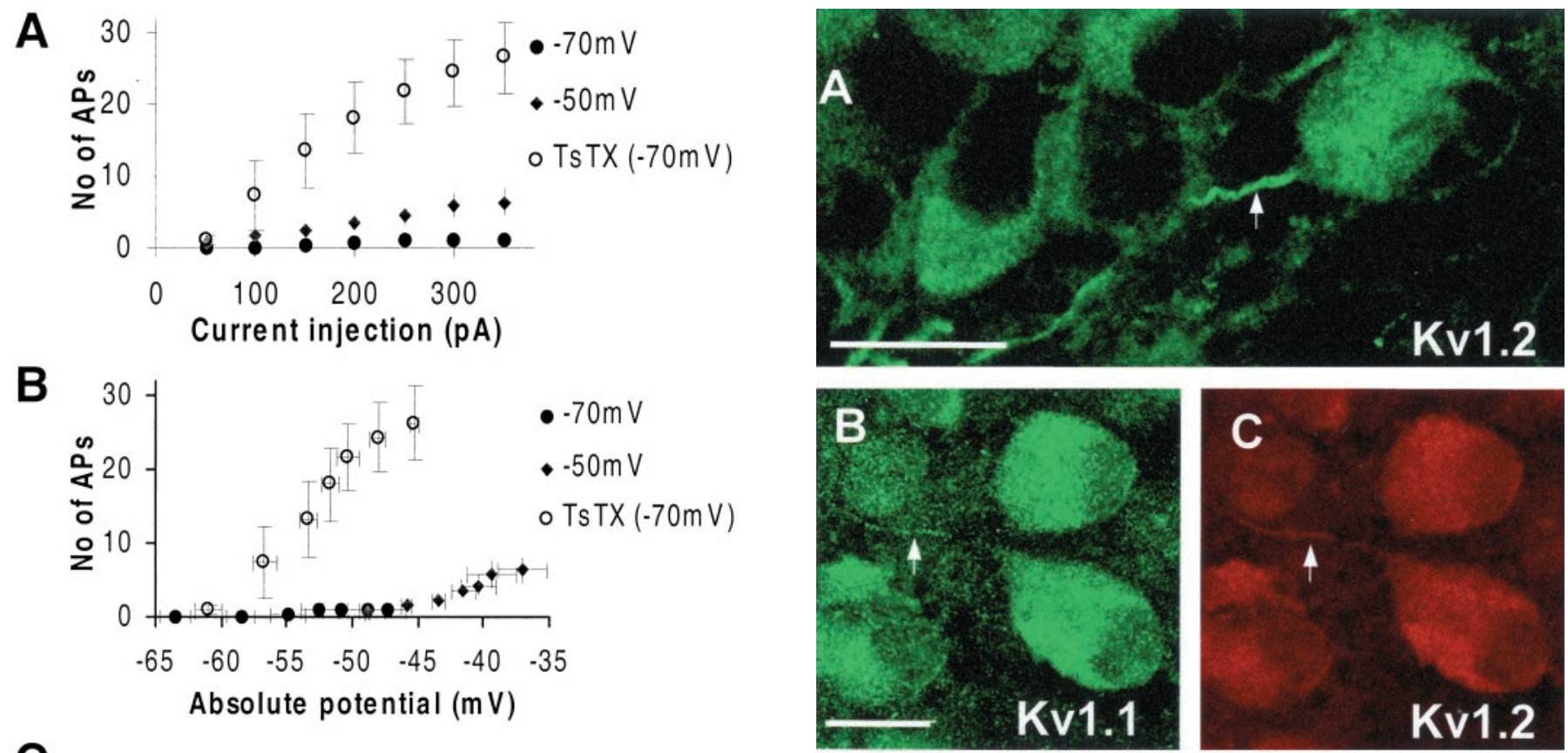

C
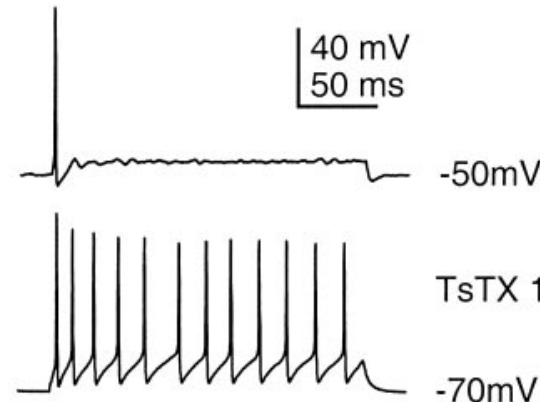

TsTX 100nM

$-70 \mathrm{mV}$

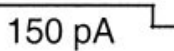

Figure 6. Multiple AP firing in TsTX is not attributable to half-block of $I_{\mathrm{LT}} . A$, The number of APs generated in response to $200 \mathrm{msec}$ current injections. More APs were fired when $I_{\mathrm{LT}}$ was half-blocked with TsTX (open circles; $n=3$ ) than when half-inactivated at a membrane potential of $-50 \mathrm{mV}$ ( filled diamonds; $n=6$ ). In control conditions, only one AP was fired throughout the range tested (filled circles; $n=6$ ). $B$, The same data are replotted as AP number against absolute potential. This was defined as the potential at the end of the current step and was equivalent to the threshold potential at high frequencies. $C$, Representative records from a current-clamped neuron depolarized from $-50 \mathrm{mV}$ in control $\mathrm{aCSF}$ and from $-70 \mathrm{mV}$ in $100 \mathrm{~nm}$ TsTX.

not responsible for the differences in AP frequency. At the same absolute membrane potential (when sodium channels will be equally inactivated), more APs are evoked in the presence of TsTX than during partial inactivation of $I_{\mathrm{LT}}($ from $-50 \mathrm{mV}$ ) (Fig. $6 B)$. In addition, at a membrane potential of $-50 \mathrm{mV}$ in the presence of TsTX, APs are continuously fired (even in the absence of current injection), suggesting that sodium channel inactivation is not sufficient to prevent repetitive firing at this potential. These data demonstrate that the difference in AP firing in the presence of TsTX at $-70 \mathrm{mV}$ and in control at $-50 \mathrm{mV}$ is not simply attributable to sodium channel inactivation.

\section{Kv1.2-containing channels are located in axons of MNTB neurons}

Although $I_{\mathrm{LTS}}$ and $I_{\mathrm{LTR}}$ contribute equally to the low-threshold current, the physiology shows that $I_{\text {LTS }}$ is of most functional
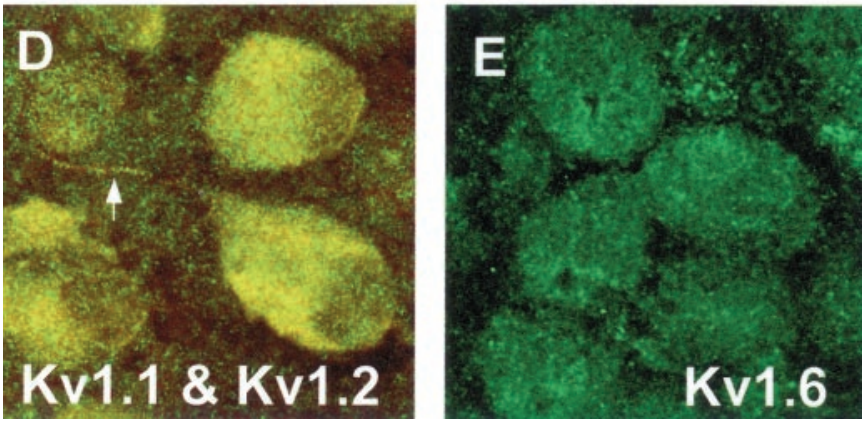

Figure 7. Kv1.1 and Kv1.2 are highly expressed in the axons of MNTB neurons. Somatic and axonal immunoreactivity can be seen for Kv1.1 and Kv1.2. Somatic but not axonal immunoreactivity can be seen for Kv1.6. A, Kv1.2 immunofluorescence with an FITC-conjugated secondary antibody. Cytoplasmic staining was observed in the soma, with no obvious additional staining at the plasma membrane. The initial $20 \mu \mathrm{m}$ of the axon has the highest level of immunoreactivity (arrows). A Z-series projection of 20 images through an MNTB neuron with a step size of $0.175 \mu \mathrm{m} . B$, Kv1.1 immunofluorescence using an FITC-conjugated secondary antibody. A Z-series projection of five images through an MNTB neuron with a step size of $0.675 \mu \mathrm{m}$. $C, \mathrm{Kv} 1.2$ immunofluorescence using a Texas Red-conjugated secondary antibody. A Z-series projection as in $B . D$, Colocalization of Kv1.1 (green) and Kv1.2 (red). The axon in $B-D$ is 1.3 $\mu \mathrm{m}$ in diameter, in contrast to axons giving rise to calyces, which are 1.5-2 $\mu \mathrm{m}$ in diameter (Forsythe, 1994). E, Kv1.6 immunofluorescence from a different section from that in $B-D$. Somatic but not axonal staining was observed ( $n=4$ animals). Scale bars, $20 \mu \mathrm{m}$ (the same scale was used for $B-E)$. Kv1.2 and Kv1.6 antibodies (Upstate Biotechnology) and a Kv1.1 antibody (Alomone Labs) were used because these had the lowest background staining.

significance in suppression of AP firing. Because the two components have similar kinetic properties, one possible explanation is that channels containing Kv1.2 are preferentially localized to an area concerned with spike initiation. To determine the subcellular location of $I_{\text {LTS }}$, we used immunohistochemical labeling of Kv1.2 viewed on a confocal microscope (Fig. $7 A$ ). Kv1.2 cytoplasmic labeling was present in the soma but there was little enhancement at the plasma membrane. The highest Kv1.2 labeling was in the initial $20 \mu \mathrm{m}$ of the axon (Fig. $7 A$, arrow). To determine whether 
Kv1.1 was expressed in the same region as Kv1.2, we used double labeling (Fig. $7 B-D$ ). Immunoreactivity for Kv1.1 and Kv1.2 was detected in the somatic cytoplasm and concentrated in the initial $20 \mu \mathrm{m}$ of the axon (arrows). The high degree of Kv1.1 overlap with Kv1.2 supports the idea that $I_{\text {LTS }}$ channels are Kv1.1/Kv1.2 heteromers. To investigate the subcellular location of $I_{\text {LTR }}$, we examined Kv1.6 labeling (Fig. 7E). Somatic Kv1.6 immunofluorescence was detected, but no axonal Kv1.6 staining was seen in the MNTB, suggesting that $I_{\text {LTR }}$ channels do not reside in the initial portion of the axon. The distribution of ion channels has important consequences for neuronal excitability, integration, and action potential firing. Although multiple sites of AP generation can exist in some neurons (Luscher and Larkum, 1998), the initial segment of an axon is of general importance for spike generation (Stuart and Sakmann, 1994). Association of $I_{\text {LTS }}$ but not $I_{\mathrm{LTR}}$ with this region may explain the dominance of $I_{\mathrm{LTS}}$ in regulating AP firing pattern in MNTB neurons.

\section{DISCUSSION}

We used immunohistochemistry, pharmacology, and electrophysiology to investigate low-threshold potassium currents $\left(I_{\mathrm{LT}}\right)$ in MNTB neurons. The data indicate that Kv1.1, Kv1.2, and Kv1.6 subunits are strongly expressed in the MNTB. These subunits assemble as heteromeric channels to produce two pharmacologically distinct currents, each of which contributes approximately one-half of the low-threshold current. One component, named $I_{\text {LTS }}$, is a low-threshold tityustoxin-sensitive current, and the other $\left(I_{\text {LTR }}\right)$ is a low-threshold tityustoxin-resistant current. The Kv1.2-containing channels that generate $I_{\text {LTS }}$ have the dominant function in determining the physiology of action potential firing in the MNTB.

Our data allow us to address two issues: first, the functional relevance of multiple low-voltage-activated currents; and second, the subunit composition of native Kv1 channels. A pharmacological approach has advantages over the use of transgenic knock-out animals to study physiological function, because we are examining native channels in the absence of compensation. Subunit-specific toxins were used to investigate the composition of $I_{\mathrm{LT}}$ channels. DTX-K and TsTX bind to specific Kv1 subunits and are thought to plug the channel pore (Ellis et al., 2001; Harvey, 2001). In heteromeric channels containing Kv1.1 and Kv1.2 subunits, only one toxin-sensitive subunit need be present for the toxin to block the channel (Hopkins, 1998). More complex binding occurs for Kv1.2/Kv1.4-containing channels, but we have no evidence for Kv1.4 in rat MNTB (from immunohistochemical, pharmacological, and electrophysiological data). Our data can also exclude the involvement of Kv1.3 and Kv1.5 subunits in $I_{\mathrm{LT}}$. Previous immunohistochemical studies have shown that Kv1.1 and Kv1.2 are expressed in brainstem nuclei in the mouse (Wang et al., 1994; Grigg et al., 2000), and our data confirm this in the rat.

We subdivided the low-threshold current in MNTB neurons into two components, $I_{\mathrm{LTS}}$ and $I_{\mathrm{LTR}}$. The simplest interpretation of the subunit composition of the channels underlying $I_{\mathrm{LTS}}$ is that

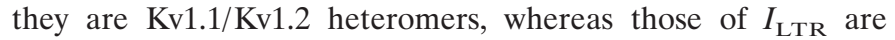
$\mathrm{Kv1.1/Kv1.6}$ heteromers. The arguments for this conclusion are developed below. First, there is no evidence for homomeric Kv1.1 or Kv1.2 channels: homomeric Kv1.1 channels are blocked by 1 mm tetraethylammonium (TEA) (Hopkins, 1998), and we saw no effect of TEA on $I_{\mathrm{LT}}$ (data not shown) (Brew and Forsythe, 1995). Similarly, $I_{\mathrm{LT}}$ is blocked by the Kv1.1-specific toxin DTX-K; this excludes homomeric Kv1.2 channels, because they would be resistant to DTX-K. Second, both components contain Kv1.1 sub- units, because $I_{\mathrm{LT}}$ is blocked by DTX-K. Third, $I_{\mathrm{LTR}}$ does not contain Kv1.2 or Kv1.3, because it is resistant to TsTX, NTX, and CP-339,818. Because Kv1.6 is the only other Kv1 subunit expressed in the MNTB, the simplest interpretation is that $I_{\mathrm{LTR}}$ is a Kv1.1/Kv1.6 heteromer and $I_{\mathrm{LTS}}$ is a $\mathrm{Kv} 1.1 / \mathrm{Kv} 1.2$ heteromer.

Evidence from studies of $\mathrm{Kv}$ subunits in expression systems suggests that $\mathrm{Kv} \alpha$ subunits associate first as dimers and then two dimers associate to form a tetramer ( $\mathrm{Tu}$ and Deutsch, 1999). If the dimer association were of general application for all Kv1 channels, then our data are compatible with a very simple hypothesis: $I_{\text {LTR }}$ is made up of two Kv1.1/Kv1.6 dimers, whereas $I_{\text {LTS }}$ is formed from Kv1.1/Kv1.2 dimers. $I_{\mathrm{LTS}}$ might include one dimer of $\mathrm{Kv1.1/Kv1.6}$ or $\mathrm{Kv1.2/Kv1.6,} \mathrm{but} \mathrm{the} \mathrm{immunohistochemistry}$ suggests that Kv1.6 is not associated with $I_{\text {LTS }}$ (Fig. 7). One caveat is that our methods are relatively insensitive to currents generated by subunit combinations, contributing $<10 \%$ of the total current. Hence, it is conceivable that some $I_{\mathrm{LT}}$ channels could include other Kv1 subunits. A possible explanation for the formation of heteromeric over homomeric channels is that particular channel subunits may have a higher affinity for different subunits, analogous to that proposed for AMPA receptors (Mansour et al., 2001). An alternative explanation is that some of the subunits present in the heteromeric channels increase the efficacy of endoplasmic reticulum (ER) export and trafficking, with homomeric channels being confined to the ER (Manganas and Trimmer, 2000).

Immunoprecipitation studies have shown that Kv1.1 and Kv1.2 are expressed in the brain as heteromers and that these heteromers can contain Kv1.6. Such heteromers can also contain Kv1.3 and Kv1.4 subunits (Koch et al., 1997; Shamotienko et al., 1997; Coleman et al., 1999), but we have no evidence for the involvement of these subunits in $I_{\mathrm{LT}}$ in MNTB neurons. In addition, Kv1.1 homomers have not been found in the brain using immunoprecipitation (Shamotienko et al., 1997; Koschak et al., 1998; Coleman et al., 1999). These findings are consistent with our proposal that $I_{\mathrm{LTS}}$ is a Kv1.1/Kv1.2 heteromer and $I_{\mathrm{LTR}}$ is a $\mathrm{Kv1.1/Kv1.6}$ heteromer, although the relatively small amount of tissue in the rat MNTB limits the application of immunoprecipitation to confirm this.

\section{Low-threshold currents maintain MNTB action potential firing pattern}

MNTB neurons fire a single action potential in response to the giant EPSP produced as a result of synaptic stimulation. A rapid EPSP is mediated by AMPA receptors, but there is also a slower NMDA receptor-mediated component (Forsythe and BarnesDavies, 1993). During high-frequency firing, this slow component would cause multiple action potentials to be fired (Brew and Forsythe, 1995). However, low-threshold potassium currents $\left(I_{\mathrm{LT}}\right)$ in MNTB neurons oppose the depolarization from the slow component and hence preserve the single AP response. $I_{\mathrm{LT}}$ in MNTB neurons acts to both keep the membrane potential below threshold during small depolarizations and bring the membrane back below threshold after a single AP. Like DTX-I and DTX-K, TsTX (which blocks $I_{\text {LTS }}$ alone) caused multiple APs in response to sustained current injection (Fig. 5). This response was not reproduced by nonspecific partial inactivation of both lowthreshold $\mathrm{K}^{+}$currents, suggesting that $I_{\mathrm{LTS}}$ has a specific function in regulating AP firing in MNTB neurons. Because $I_{\text {LTS }}$ and $I_{\text {LTR }}$ have similar properties, it seems unlikely that this differential function is the result of kinetic differences. One explanation for the dominance of $I_{\text {LTS }}$ in determining AP firing pattern would be 
that $I_{\mathrm{LTS}}$ is preferentially localized to the spike initiation region. The immunohistochemistry confirmed that Kv1.2 (and therefore $\left.I_{\text {LTS }}\right)$ is highly expressed in the initial region of MNTB axons (Fig. 7A,C, arrows), although cytoplasmic staining of both Kv1.1 and Kv1.2 makes it difficult to determine differential location of these subunits in the somatic membrane. Somatic but not axonal immunoreactivity was observed for Kv1.6 (Fig. 7E), suggesting that channels underlying $I_{\mathrm{LTR}}$ are not located in the initial region of the axon. Differential distribution of $\mathrm{K}^{+}$channels has been observed in rat spinal cord neurons, with delayed rectifier channels being concentrated in axons and dendrites and at low levels on the soma (Wolff et al., 1998). Trafficking to the cell surface is enhanced by association with some $\operatorname{Kv} \beta$ subunits (Manganas and Trimmer, 2000), and, in cultured hippocampal neurons, coexpression with $\mathrm{Kv} \beta 2$ results in axonal targeting of Kv1.2 (Campomanes et al., 2002). Immunoprecipitation studies have found that $\mathrm{Kv} \beta 2.1$ subunits are expressed in neurons with channels containing Kv1.2 (Shamotienko et al., 1997; Coleman et al., 1999). Other proteins such as Caspr and Caspr2 have also been implicated in localizing Kv1.1 and Kv1.2 to jutaparanodal regions of myelinated axons (Poliak et al., 1999). It is conceivable that $\mathrm{Kv} \beta 2$ or Caspr proteins may preferentially associate with $I_{\text {LTS }}$ and contribute to the differential localization of $I_{\text {LTS }}$ and $I_{\text {LTR }}$. If $\mathrm{Kv} \beta 1.1$ subunits, which confer N-type inactivation, were also present, this could account for the partial inactivation of $I_{\mathrm{LT}}$ (Fig. $2 A$ ).

The role of $I_{\mathrm{LTR}}$ is not clear, but it would certainly bolster the low-threshold conductance during large depolarizations and would also support differential modulation by second messengers. For instance, PKC inhibits Kv1.1 (Boland and Jackson, 1999), whereas PKA increases Kv1.1 and Kv1.2 currents (Huang et al., 1994; Levin et al., 1995; Jonas and Kaczmarek, 1996). Phosphorylation by tyrosine kinases suppresses Kv1.2 current (Lev et al., 1995; Holmes et al., 1996). However, the effect of phosphorylation on heteromeric channels such as $I_{\text {LTS }}$ and $I_{\text {LTR }}$ may differ from homomeric channels.

\section{Similar DTX-sensitive currents in other neurons}

Several DTX-sensitive low-threshold currents similar to $I_{\mathrm{LT}}$ have been found in other neurons in rat, mouse, and avian brain. These currents are often found in neurons with similar firing properties and are responsible for maintaining the single AP response. Such currents are present in mammalian bushy cells of the cochlear nucleus (Manis and Marx, 1991), the nucleus magnocellularis (the avian homolog of the bushy cells) (Rathouz and Trussell, 1998), octopus cells of the cochlear nucleus (Bal and Oertel, 2001), neocortical pyramidal neurons (Bekkers and Delaney, 2001), embryonic central vestibular neurons (Gamkrelidze et al., 1998), in basket cell terminals (Southan and Robertson, 2000), and $I_{\mathrm{D}}$ in hippocampal neurons (Wu and Barish, 1992). These currents are likely to be mediated by Kv1 heteromers similar to $I_{\text {LTR }}$ and $I_{\text {LTS }}$.

\section{REFERENCES}

Bal R, Oertel D (2001) Potassium currents in octopus cells of the mammalian cochlear nucleus. J Neurophysiol 86:2299-2311.

Barnes-Davies M, Forsythe ID (1995) Pre- and postsynaptic glutamate receptors at a giant excitatory synapse in rat auditory brainstem slices. J Physiol (Lond) 488:387-406.

Bekkers JM, Delaney AJ (2001) Modulation of excitability by $\alpha$-dendrotoxin-sensitive potassium channels in neocortical pyramidal neurons. J Neurosci 21:6553-6560.

Boland LM, Jackson KA (1999) Protein kinase C inhibits Kv1.1 potassium channel function. Am J Physiol 46:C100-C110.

Brew HM, Forsythe ID (1995) Two voltage-dependent $\mathrm{K}^{+}$conduc- tances with complementary functions in postsynaptic integration at a central auditory synapse. J Neurosci 15:8011-8022.

Campomanes CR, Carroll KI, Manganas LN, Hershberger ME, Gong B, Antonucci DE, Rhodes KJ, Trimmer JS (2002) Kvbeta subunit oxidoreductase activity and Kv1 potassium channel trafficking. J Biol Chem 277:8298-8305.

Coetzee WA, Amarillo Y, Chiu J, Chow A, Lau D, McCormack T, Moreno H, Nadal MS, Ozaita A, Pountney D, Saganich M, Vega-Saenz de Miera E, Rudy B (1999) Molecular diversity of $\mathrm{K}^{+}$channels. Ann NY Acad Sci 868:233-285.

Coleman SK, Newcombe J, Pryke J, Dolly JO (1999) Subunit composition of Kv1 channels in human CNS. J Neurochem 73:849-858.

Ellis KC, Tenenholz TC, Jerng H, Hayhurst M, Dudlak CS, Gilly WF, Blaustein MP, Weber DJ (2001) Interaction of a toxin from the scorpion Tityus serrulatus with a cloned $\mathrm{K}^{+}$channel from squid (sqKv1A). Biochemistry 40:5942-5953.

Forsythe ID (1994) Direct patch recording from identified presynaptic terminals mediating glutamatergic EPSCs in the rat CNS, in vitro. J Physiol (Lond) 479:381-387.

Forsythe ID, Barnes-Davies M (1993) The binaural auditory pathway: excitatory amino acid receptors mediate dual timecourse excitatory postsynaptic currents in the rat medial nucleus of the trapezoid body. Proc R Soc Lond B Biol Sci 251:151-157.

Gamkrelidze G, Giaume C, Peusner KD (1998) The differential expression of low-threshold sustained potassium current contributes to the distinct firing patterns in embryonic central vestibular neurons. J Neurosci 18:1449-1464.

Grigg JJ, Brew HM, Tempel BL (2000) Differential expression of voltage-gated potassium channel genes in auditory nuclei of the mouse brainstem. Hear Res 140:77-90.

Grissmer S, Nguyen AN, Aiyar J, Hanson DC, Mather RJ, Gutman GA Karmilowicz MJ, Auperin DD, Chandy KG (1994) Pharmacological characterization of five cloned voltage-gated $\mathrm{K}^{+}$channels, types Kv1.1, $1.2,1.3,1.5$, and 3.1 , stably expressed in mammalian cell lines. Mol Pharmacol 45:1227-1234.

Harvey AL (2001) Twenty years of dendrotoxins. Toxicon 39:15-26.

Hille B (2001) Ion channels of excitable membranes. Ed 3. Sunderland, MA: Sinauer.

Holmes TC, Fadool DA, Levitan IB (1996) Tyrosine phosphorylation of the Kv1.3 potassium channel. J Neurosci 16:1581-1590.

Hopkins WF (1998) Toxin and subunit specificity of blocking affinity of three peptide toxins for heteromultimeric, voltage-gated potassium channels expressed in Xenopus oocytes. J Pharmacol Exp Ther 285:1051-1060.

Huang X, Morielli A, Peralta E (1994) Molecular basis of cardiac potassium channel stimulation by protein kinase A. Proc Natl Acad Sci USA 91:624-628.

Isacoff EY, Jan YN, Jan LY (1990) Evidence for the formation of heteromultimeric potassium channels in Xenopus oocytes. Nature 345:530-534.

Jager H, Rauer H, Nguyen AN, Aiyar J, Chandy KG, Grissmer S (1998) Regulation of mammalian Shaker-related $\mathrm{K}^{+}$channels: evidence for non-conducting closed and non-conducting inactivated states. J Physiol (Lond) 506:291-301.

Jonas EA, Kaczmarek LK (1996) Regulation of potassium channels by protein kinases. Curr Opin Neurobiol 6:318-323.

Kalman K, Nguyen A, Tseng-Crank J, Dukes ID, Chandy G, Hustad CM, Copeland NG, Jenkins NA, Mohrenweiser H, Brandriff B, Cahalan M, Gutman GA, Chandy KG (1998) Genomic organization, chromosomal localization, tissue distribution, and biophysical characterization of a novel mammalian Shaker-related voltage-gated potassium channel, Kv1.7. J Biol Chem 273:5851-5857.

Kashuba VI, Kvasha SM, Protopopov AI, Gizatullin RZ, Rynditch AV, Wahlestedt C, Wasserman WW, Zabarovsky ER (2001) Initial isolation and analysis of the human Kv1.7 (KCNA7) gene, a member of the voltage-gated potassium channel gene family. Gene 268:115-122.

Koch RO, Wanner SG, Koschak A, Hanner M, Schwarzer C, Kaczorowski GJ, Slaughter RS, Garcia ML, Knaus H-G (1997) Complex subunit assembly of neuronal voltage-gated $\mathrm{K}^{+}$channels. J Biol Chem 272:27577-27581.

Koschak A, Bugianesi RM, Mitterdorfer J, Kaczorowski GJ, Garcia ML, Knaus HG (1998) Subunit composition of brain voltage-gated potassium channels determined by hongotoxin-1, a novel peptide derived from Centruroides limbatus venom. J Biol Chem 273:2639-2644.

Lev S, Moreno H, Martinez R, Canoll P, Peles E, Musacchio JM, Plowman GD, Rudy B, Schlessinger J (1995) Protein tyrosine kinase PYK2 involved in $\mathrm{Ca}^{2+}$-induced regulation of ion channel and MAP kinase functions. Nature 376:737-745.

Levin G, Keren T, Peretz T, Chikvashvili D, Thornhill WB, Lotan I (1995) Regulation of RCK1 currents with a cAMP analog via enhanced protein synthesis and direct channel phosphorylation. J Biol Chem 270:14611-14618.

Luscher HR, Larkum ME (1998) Modeling action potential initiation and back-propagation in dendrites of cultured rat motoneurons. J Neurophysiol 80:715-729. 
Macica CM, Kaczmarek LK (2001) Casein kinase 2 determines the voltage dependence of the Kv3.1 channel in auditory neurons and transfected cells. J Neurosci 21:1160-1168.

Manganas LN, Trimmer JS (2000) Subunit composition determines Kv1 potassium channel surface expression. J Biol Chem 275:29685-29693.

Manis PB, Marx SO (1991) Outward currents in isolated ventral cochlear nucleus neurons. J Neurosci 11:2865-2880.

Mansour M, Nagarajan N, Nehring RB, Clements JD, Rosenmund C (2001) Heteromeric AMPA receptors assemble with a preferred subunit stoichiometry and spatial arrangement. Neuron 32:841-853.

Matteson DR, Blaustein MP (1997) Scorpion toxin block of the early $\mathrm{K}^{+}$current (IKf) in rat dorsal root ganglion neurones. J Physiol (Lond) 503:285-301.

Nguyen A, Kath JC, Hanson DC, Biggers MS, Canniff PC, Donovan CB, Mather RJ, Bruns MJ, Rauer H, Aiyar J, Lepple-Wienhues A, Gutman GA, Grissmer S, Cahalan MD, Chandy KG (1996) Novel non-peptide agents potently block the C-type inactivated conformation of Kv1.3 and suppress T cell activation. Mol Pharmacol 50:1672-1679.

Park TJ, Grothe B, Pollak GD, Schuller G, Koch U (1996) Neural delays shape selectivity to interaural intensity differences in the lateral superior olive. J Neurosci 16:6554-6566.

Poliak S, Gollan L, Martinez R, Custer A, Einheber S, Salzer JL, Trimmer JS, Shrager P, Peles E (1999) Caspr2, a new member of the neurexin superfamily, is localized at the juxtaparanodes of myelinated axons and associates with $\mathrm{K}^{+}$channels. Neuron 24:1037-1047.

Rathouz M, Trussell L (1998) Characterization of outward currents in neurons of the avian nucleus magnocellularis. J Neurophysiol $80: 2824-2835$.

Robertson B, Owen D, Stow J, Butler C, Newland C (1996) Novel effects of dendrotoxin homologues on subtypes of mammalian Kv1 potassium channels expressed in Xenopus oocytes. FEBS Lett 383:26-30.

Rudy B, McBain CJ (2001) Kv3 channels: voltage-gated $\mathrm{K}^{+}$channels designed for high-frequency repetitive firing. Trends Neurosci 24:517-526.

Ruppersberg JP, Schroter KH, Sakmann B, Stocker M, Sewing S, Pongs O (1990) Heteromultimeric channels formed by rat brain potassiumchannel proteins. Nature 345:535-537.

Shamotienko OG, Parcej DN, Dolly JO (1997) Subunit combinations defined for $\mathrm{K}^{+}$channel Kv1 subtypes in synaptic membranes from bovine brain. Biochemistry 36:8195-8201.

Southan AP, Robertson B (2000) Electrophysiological characterization of voltage-gated $\mathrm{K}^{+}$currents in cerebellar basket and Purkinje cells: Kv1 and Kv3 channel subfamilies are present in basket cell nerve terminals. J Neurosci 20:114-122.

Stuart GJ, Sakmann B (1994) Active propagation of somatic action potentials into neocortical pyramidal cell dendrites. Nature 367:69-72.

Taschenberger H, von Gersdorff H (2000) Fine-tuning an auditory synapse for speed and fidelity: developmental changes in presynaptic waveform, EPSC kinetics, and synaptic plasticity. J Neurosci 20:9162-9173.

Trussell LO (1999) Synaptic mechanisms for coding timing in auditory neurons. Annu Rev Physiol 61:477-496.

Tu L, Deutsch C (1999) Evidence for dimerization of dimers in $\mathrm{K}^{+}$ channel assembly. Biophys J 76:2004-2017.

Tytgat J, Chandy KG, Garcia ML, Gutman GA, Martin-Eauclaire MF, van der Walt JJ, Possani LD (1999) A unified nomenclature for shortchain peptides isolated from scorpion venoms: alpha-KTx molecular subfamilies. Trends Pharmacol Sci 20:444-447.

Wang FC, Bell N, Reid P, Smith LA, McIntosh P, Robertson B, Dolly JO (1999a) Identification of residues in dendrotoxin $\mathrm{K}$ responsible for its discrimination between neuronal $\mathrm{K}^{+}$channels containing Kv1.1 and 1.2 alpha subunits. Eur J Biochem 263:222-229.

Wang FC, Parcej DN, Dolly JO (1999b) alpha subunit compositions of Kv1.1-containing $\mathrm{K}^{+}$channel subtypes fractionated from rat brain using dendrotoxins. Eur J Biochem 263:230-237.

Wang H, Kunkel DD, Schwartzkroin PA, Tempel BL (1994) Localization of Kv1.1 and Kv1.2, 2 K-channel proteins, to synaptic terminals, somata, and dendrites in the mouse brain. J Neurosci 14:4588-4599.

Wang LY, Gan L, Forsythe ID, Kaczmarek LK (1998) Contribution of the Kv3.1 potassium channel to high-frequency firing in mouse auditory neurones. J Physiol (Lond) 509:183-194.

Wolff M, Vogel W, Safronov BV (1998) Uneven distribution of $\mathrm{K}^{+}$ channels in soma, axon and dendrites of rat spinal neurones: functional role of the soma in generation of action potentials. J Physiol (Lond) 509:767-776.

Wu RL, Barish ME (1992) Two pharmacologically and kinetically distinct transient potassium currents in cultured embryonic mouse hippocampal neurons. J Neurosci 12:2235-2246.

Xu J, Yu W, Wright JM, Raab RW, Li M (1998) Distinct functional stoichiometry of potassium channel beta subunits. Proc Natl Acad Sci USA 95:1846-1851. 